Article

\title{
Electrochemical Performance of Iron Oxide Nanoflakes on Carbon Cloth under an External Magnetic Field
}

\author{
Lei Geng ${ }^{1, *}$, Zenglai Gao ${ }^{1}$ and Qibo Deng ${ }^{2}$ (I) \\ 1 Tianjin Key Laboratory of Optoelectronic Detection Technology and Systems, School of Electronics and \\ Information Engineering, Tianjin Polytechnic University, No. 399 Binshui West Street Xiqing District, \\ Tianjin 300387, China; 15922161767@163.com \\ 2 Tianjin Key Laboratory of Advanced Functional Porous Materials, Institute for New Energy Materials \& \\ Low-Carbon Technologies, School of Materials Science and Engineering, Tianjin University of Technology, \\ No. 391 Binshui West Street Xiqing District, Tianjin 300384, China; qibodeng@tjut.edu.cn \\ * Correspondence: genglei@tjpu.edu.cn; Tel.: +86-022-8395-5164
}

Received: 22 October 2018; Accepted: 11 November 2018; Published: 13 November 2018

\begin{abstract}
In this work, the iron oxide $\left(\mathrm{Fe}_{2} \mathrm{O}_{3}\right)$ nanoflakes on carbon cloth $\left(\mathrm{Fe}_{2} \mathrm{O}_{3} @ \mathrm{CC}\right)$ were triumphantly prepared and served as the electrode of supercapacitors. By applying an external magnetic field, we first find that the magnetic field could suppress the polarization phenomenon of electrochemical performance. Then, the influences of the mono-/bi-valent cations on the electrochemical properties of the $\mathrm{Fe}_{2} \mathrm{O}_{3} @ \mathrm{CC}$ were investigated under a large external magnetic field $(1 \mathrm{~T})$ in this work. The chemical valences of the cations in the aqueous electrolytes $\left(\mathrm{LiNO}_{3}\right.$ and $\left.\mathrm{Ca}\left(\mathrm{NO}_{3}\right)_{2}\right)$ have almost no influences on the specific capacitance at different scan rates. As one of important parameters to describe the electrochemical properties, the working potential window of the $\mathrm{Fe}_{2} \mathrm{O}_{3} @ \mathrm{CC}$ electrode was also investigated in this work. The broad potential window in room-temperature molten salt ( $\left.\mathrm{LiTFSI}+\mathrm{LiBETI}\left(\mathrm{LiN}\left(\mathrm{SO}_{2} \mathrm{CF}_{3}\right)_{2}+\mathrm{LiN}\left(\mathrm{SO}_{2} \mathrm{C}_{2} \mathrm{~F}_{5}\right)_{2}\right)\right)$ has been obtained and reached $1.2 \mathrm{~V}$, which is higher than that of the traditional aqueous electrolyte $(\sim 0.9 \mathrm{~V})$.
\end{abstract}

Keywords: $\mathrm{Fe}_{2} \mathrm{O}_{3}$ nanoflakes; magnetic field; molten salt; wide working windows; electrochemical capacitors

\section{Introduction}

Electrochemical capacitors have been considered as a reliable supplement in power sources aspect, which is due to their fast charging/discharging processing, good cycling properties and high power density [1-3]. Nevertheless, their low energy density becomes a stumbling block to the rapid development of supercapacitors. In order to get higher energy density several strategies have been explored to design and fabricate electrode materials with various porous and hierarchical nanostructures, which are conducive to enhance specific capacitances and modify the rate performances [4-8]. Iron oxides (such as $\mathrm{Fe}_{2} \mathrm{O}_{3}$ and $\mathrm{Fe}_{3} \mathrm{O}_{4}$ ) have been brought into focus as electrode candidates for supercapacitors in a variety of materials [9-12]. Specifically, $\alpha-\mathrm{Fe}_{2} \mathrm{O}_{3}$ materials have been synthesized and reported elsewhere because of their high theoretical capacitance, low cost, and abundant chemical valences. Currently, various $\alpha-\mathrm{Fe}_{2} \mathrm{O}_{3}$ nanostructures, for instance nanoparticles, nanotubes, nanosheets, and nanospheres with high super-paramagnetic behaviors, porous structure, and high surface area have been researched and exhibited excellent electrochemical properties [13-17]. However, the weak electrical conductivity of $\alpha-\mathrm{Fe}_{2} \mathrm{O}_{3}$ materials $\left(10^{-4} \Omega^{-1} \cdot \mathrm{m}^{-1}\right.$ for bulk and $2.5 \times 10^{-3} \Omega^{-1} \cdot \mathrm{m}^{-1}$ for nanostructures) still makes it difficult to completely use the active material, giving rise to finite enhancement of the specific capacitance [18-20]. There is literature 
reporting that very small external magnetic fields $(\mathrm{mT})$ have induced capacitance enhancement of the $\mathrm{Fe}_{2} \mathrm{O}_{3}$-graphene nanocomposites [21]. This could explain why the external magnetic field is deemed to facilitate the electrons/ions transmission between the electrolyte and the electrode during charging/discharging procedure. However, one wonders if the very large magnetic field has an effect on the capacitance. More recently, a finer morphology of nanoporous magnetic material has been prepared by applying an external magnetic field $(\sim 0.5 \mathrm{~T})$ which modulates different dealloying stages of the nanoporous structure formation. We have reported the effect of an external magnetic field on the dealloying process of the $\mathrm{Ni}-\mathrm{Al}$ alloy in alkaline solution [22].

Munichandraiah et al. found that the aqueous electrolytes with bivalent cations $\mathrm{CCa}^{2+}$ or $\mathrm{Mg}^{2+}$ ) contributed to modify the $\mathrm{MnO}_{2}$ electrochemical utilization and, thus, improved the specific capacitance $[23,24]$. However, the common aqueous electrolytes cannot overcome the thermodynamic limitation of water splitting, $\sim 1.23 \mathrm{~V}[25,26]$, and the non-aqueous electrolytes (e.g., organic electrolytes) are generally combustible and expensive. Over the years, the inventive "water-in-salt" hybrids and room-temperature molten salts have been proven to broad the working voltage window (much larger than $1.23 \mathrm{~V}$ ) [27-29]. Herein, this work investigates the influences of the mono-/bi-valent cations on the electrochemical properties of the $\mathrm{Fe}_{2} \mathrm{O}_{3} @$ carbon cloth $\left(\mathrm{Fe}_{2} \mathrm{O}_{3} @ \mathrm{CC}\right)$ under an external magnetic field $(1 \mathrm{~T})$. The electrochemical performances of the $\mathrm{Fe}_{2} \mathrm{O}_{3} @ \mathrm{CC}$ electrode in a room-temperature molten salt electrolyte have been also studied for the broad working potential window.

\section{Materials and Methods}

The carbon cloth (WOS 1002 PHYCHEMi Co., Ltd., Wuhan, China) in the work was conducted the hydrophilic treatment. The detailed process is following: the carbon cloth was washed with concentrated $\mathrm{H}_{2} \mathrm{SO}_{4}$ and $\mathrm{H}_{2} \mathrm{O}_{2}$ mixed solution, and deionized water under sonication for $2 \mathrm{~h}$. The treated carbon cloth (CC) served as the substrate for the growth of $\mathrm{Fe}_{2} \mathrm{O}_{3}$ nanoflakes. Electrochemical deposition was performed at $1.5 \mathrm{~V}$ for $5 \mathrm{~min}$ in a conventional three-electrode system: the treated $\mathrm{CC}$, the $\mathrm{Pt}$, and an $\mathrm{Ag} / \mathrm{AgCl}$ as the working, counter and reference electrodes, respectively. The working electrolyte was $0.05 \mathrm{M} \mathrm{FeCl}_{2}$ aqueous solution for iron deposition. Then the working electrode was washed with deionized water and ethanol, and dried for a night. Lastly, the dried precursors were calcinated at $650{ }^{\circ} \mathrm{C}$ for $2 \mathrm{~h}$ in an inert atmosphere.

The structural information, constitute and morphology features of the $\mathrm{Fe}_{2} \mathrm{O}_{3} @ \mathrm{CC}$ composites were determined by X-ray diffraction (XRD, Rigaku D/Max-2500, Japan) with native Standard Measurement software, and field emission scanning electron microscopy (FESEM, FEI Verios 460 L, Eindhoven, The Netherlands). The electrochemical measurements were carried out in a three-electrode system: the $\mathrm{Fe}_{2} \mathrm{O}_{3} @ \mathrm{CC}(5 \times 5 \mathrm{~mm})$, the $\mathrm{Pt}(50 \times 50 \mathrm{~mm})$ and $\mathrm{Ag} / \mathrm{AgCl}$ were used as working electrode, counter electrode, and reference electrode, respectively. All electrochemical measurements were carried out under an external magnetic field (EMP-5, East Changing, Beijing, China). The magnetic field was controlled through adjusting the magnitude of the current and the magnetic flux density was then measured by a Digital Gauss Meter (PF-045B, Mianyang, China). The direction of magnetic field was perpendicular to the surface of working electrode. Cyclic voltammetry $(\mathrm{CV})$ and electrochemical impedance spectroscopy (EIS) of the $\mathrm{Fe}_{2} \mathrm{O}_{3} @ \mathrm{CC}$ electrode were performed using electrochemical workstation (CHI 760E, Shanghai, China) in different aqueous electrolytes of $1 \mathrm{M} \mathrm{LiNO}_{3}, 1 \mathrm{M} \mathrm{Li}_{2} \mathrm{SO}_{4}$, $1 \mathrm{M} \mathrm{KNO}_{3}, 1 \mathrm{M} \mathrm{Ca}\left(\mathrm{NO}_{3}\right)_{2}$, and $1 \mathrm{M} \mathrm{LiTFSI}+\mathrm{LiBETI}$.

\section{Results and Discussion}

The phase and constitute of the composites were characterized by XRD analysis and the corresponding result is shown in Figure 1. The distinct diffraction peak located at around $25^{\circ}$ can be ascribed to the carbon cloth substrate. Although the intensity of the remaining peaks is very weak, the peak positions can be matched well with the $\mathrm{Fe}_{2} \mathrm{O}_{3}$ (JCPDS No. 04-755), demonstrating the triumphant preparation of the $\mathrm{Fe}_{2} \mathrm{O}_{3} @ \mathrm{CC}$ composite. The crystallite size of the $\mathrm{Fe}_{2} \mathrm{O}_{3}$ phase from XRD pattern was $3.7 \mathrm{~nm}$ estimated by using the Scherrer equation. 


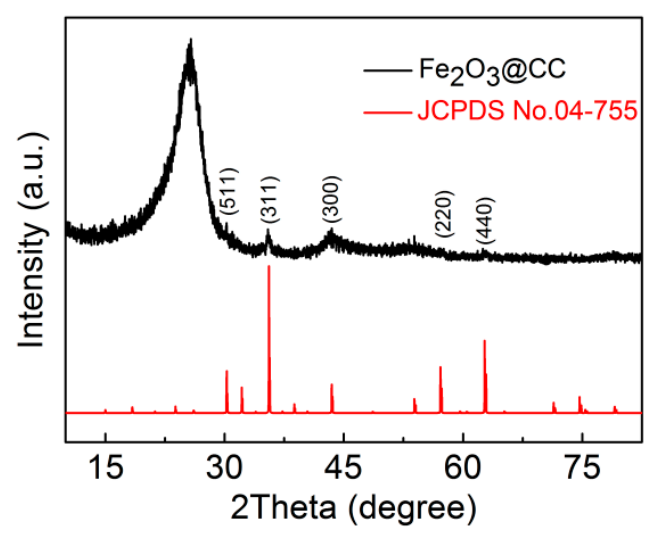

Figure 1. XRD pattern of the $\mathrm{Fe}_{2} \mathrm{O}_{3} @ \mathrm{CC}$ composite.

Figure 2 shows the microstructure of the $\mathrm{Fe}_{2} \mathrm{O}_{3} @ \mathrm{CC}$ composite electrode. After electrochemical deposition, the whole braided structure of the carbon cloth is successfully maintained and the diameter of the carbon fiber is approximately unchanged. Comparing to the smooth surface of the carbon cloth, the $\mathrm{Fe}_{2} \mathrm{O}_{3} @ \mathrm{CC}$ composite exhibits a rough surface, which indicates the successful deposition of $\mathrm{Fe}_{2} \mathrm{O}_{3}$. In Figure $2 \mathrm{~b}$, the flimsy $\mathrm{Fe}_{2} \mathrm{O}_{3}$ nanoflakes with around $20 \mathrm{~nm}$ thickness are interconnecting and uniformly decorate the carbon fiber.
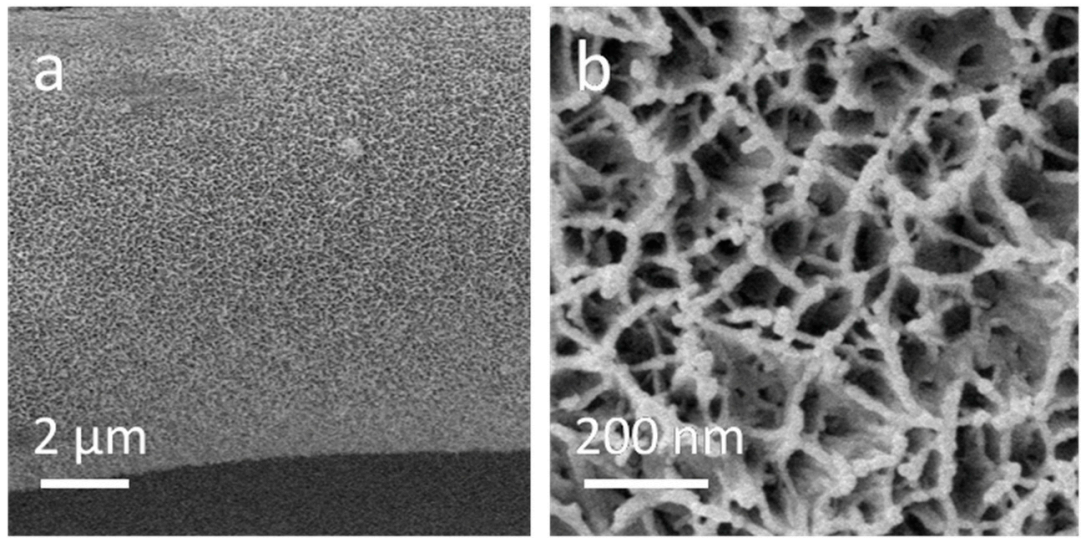

Figure 2. Low-resolution SEM image (a) and high-resolution SEM image (b) of the $\mathrm{Fe}_{2} \mathrm{O}_{3} @ C C$ composite.

To verify the external magnetic field effect on the electrochemical performances of the $\mathrm{Fe}_{2} \mathrm{O}_{3} @ \mathrm{CC}$ electrode, the CVs were carried out in different electrolytes with or without applying an external magnetic field and the results are shown in Figure 3. In Figure 3a, it is seen that the contribution from the CC substrate can be negligible and the specific capacitance of the $\mathrm{Fe}_{2} \mathrm{O}_{3} @ C C$ electrode is mainly from the contribution of $\mathrm{Fe}_{2} \mathrm{O}_{3}$. In terms of $\mathrm{CV}$ shape, the specific capacitance of the $\mathrm{Fe}_{2} \mathrm{O}_{3} @ \mathrm{CC}$ electrode is the combination of the double layer and pseudo-capacitive characteristic [30-32]. The specific capacitances of the $\mathrm{Fe}_{2} \mathrm{O}_{3} @ \mathrm{CC}$ electrode are almost the same by integrating the enclosed area with or without the external magnetic field. But their shapes of the CV curves have some differences to a certain extent. Concretely, the polarization phenomenon of the $\mathrm{CV}$ plot is obtaining efficient control when adding the external magnetic field. That is to say, the splitting of water in the electrolyte is suppressed by the external magnetic field. Therefore, the following electrochemical tests in different aqueous electrolytes are conducted under the external magnetic field. Figure 3 depicts $\mathrm{CV}$ plots of the $\mathrm{Fe}_{2} \mathrm{O}_{3} @ C C$ electrode in various aqueous electrolytes of $1 \mathrm{M} \mathrm{Li}_{2} \mathrm{SO}_{4}, 1 \mathrm{MLiNO}_{3}, 1 \mathrm{MKNO}_{3}$, and $1 \mathrm{MCa}\left(\mathrm{NO}_{3}\right)_{2}$, for exploring the better specific capacitance.The measurements were performed at the magnetic flux density $(1 \mathrm{~T})$. Among the $\mathrm{CV}$ in monovalent cationic electrolytes, the one in $\mathrm{LiNO}_{3}$ solution presents the largestenclosed area. The $\mathrm{CV}$ plot shapes are nearly the same for the bivalent case, 
suggesting the same electrochemical procedure. Moreover, the enclosed areas in CV for the bivalent casepossess larger enclosed area than that in $\mathrm{LiNO}_{3}$ solution.
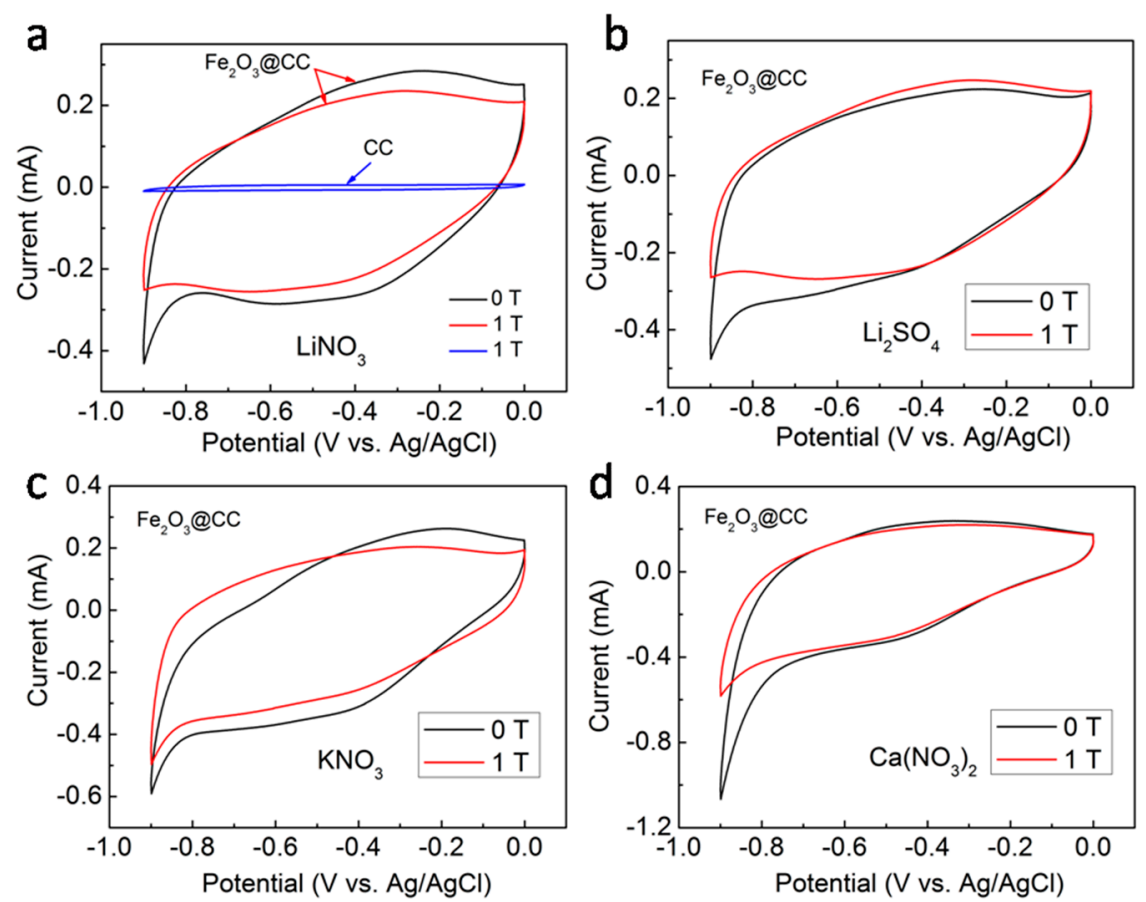

Figure 3. $\mathrm{CV}$ curves of the $\mathrm{Fe}_{2} \mathrm{O}_{3} @ \mathrm{CC}$ and $\mathrm{CC}$ electrodes with or without magnetic field in various aqueous electrolyte: (a) $\mathrm{LiNO}_{3}$, (b) $\mathrm{Li}_{2} \mathrm{SO}_{4}$, (c) $\mathrm{KNO}_{3}$, and (d) $\mathrm{Ca}\left(\mathrm{NO}_{3}\right)_{2}$.

The variation of the corresponding specific capacitance with the scan rates of the $\mathrm{Fe}_{2} \mathrm{O}_{3} @ C C$ electrode in different electrolytes has exhibited in Figure 4. The calculated specific capacitance of the $\mathrm{Fe}_{2} \mathrm{O}_{3} @ \mathrm{CC}$ electrode measured in $1 \mathrm{M} \mathrm{Li}_{2} \mathrm{SO}_{4}$ electrolyte are 52, 40, 29, 26, 23, and $19 \mathrm{mF} \mathrm{cm}^{-2}$ at $1,2,5,8,10$, and $20 \mathrm{mV} \mathrm{s}^{-1}$, respectively. As reported in the literature, the specific capacitances reduce with increase in the scan rate in any electrolytes [33-36]. The situation could be seen in other electrolytes. The values of specific capacitance obtained in $1 \mathrm{M} \mathrm{LiNO}_{3}$ solution are 53, 44, 28, 24, 24, and $18 \mathrm{mF} \cdot \mathrm{cm}^{-2}$, respectively. However, these values obtained in $1 \mathrm{M} \mathrm{KNO}_{3}$ solution decrease to $30,24,20,17,15$, and $9 \mathrm{mF} \cdot \mathrm{cm}^{-2}$, respectively. The slightly higherspecific capacitance of $\mathrm{Fe}_{2} \mathrm{O}_{3} @ \mathrm{CC}$ electrodeobtained in lithium ions electrolyte could be ascribed to more effortless migration for lithium ions. It possesses the applicable crystal size $\left(0.69 \AA\right.$ for $\mathrm{Li}^{+}, 1.38 \AA$ for $\mathrm{K}^{+}$, and $0.99 \AA$ for $\left.\mathrm{Ca}^{2+}\right)$ [37]. Simultaneously, the lower saturated concentration of the $\mathrm{KNO}_{3}$ solution (only $3.1 \mathrm{M}$, about $10 \mathrm{M}$ for $\mathrm{LiNO}_{3}$ ) results in its lowest specific capacitances at all scan rates. Interestingly, the specific capacitance, variation trend and retention are practically consistent in both $\mathrm{LiNO}_{3}$ and $\mathrm{Ca}\left(\mathrm{NO}_{3}\right)_{2}$ solutions. Thus, the different valence of the cations in the electrolytes has no effects on the electrochemical performances of the $\mathrm{Fe}_{2} \mathrm{O}_{3} @ \mathrm{CC}$ electrode. 


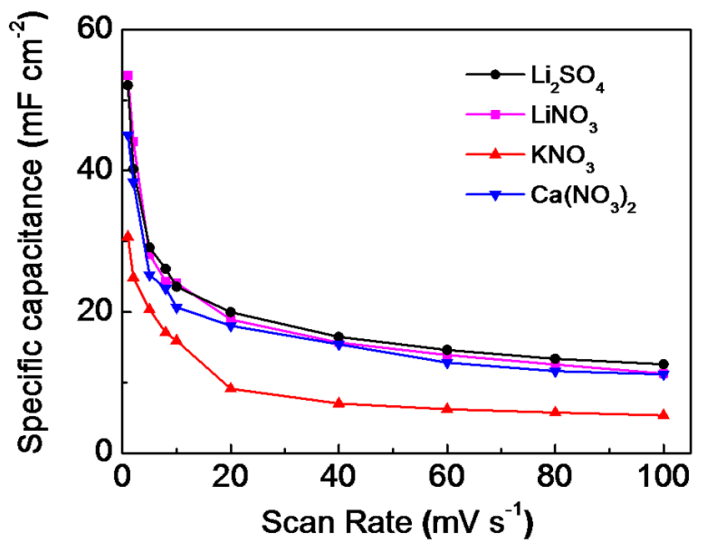

Figure 4. The corresponding variation of the specific capacitances with the scan rate of the $\mathrm{Fe}_{2} \mathrm{O}_{3} @ \mathrm{CC}$ electrode in different electrolytes.

EIS measurements were carried out to get more information about the impact of the cations valency on the electrochemical properties of the $\mathrm{Fe}_{2} \mathrm{O}_{3} @ C C$ electrode. Using Zview software (V2.0.1.6, Southern Pines, NC, USA), the equivalent circuit and the best fitting of Nyquist plots in $\mathrm{LiNO}_{3}$ and $\mathrm{Ca}\left(\mathrm{NO}_{3}\right)_{2}$ solutions are exhibited in Figure 5. The best fitting gives the $\mathrm{R}_{\mathrm{S}}$ values for the $\mathrm{Fe}_{2} \mathrm{O}_{3} @ \mathrm{CC}$ electrode in $\mathrm{LiNO}_{3}$ and $\mathrm{Ca}\left(\mathrm{NO}_{3}\right)_{2}$ solutionas2.32 and $2.34 \Omega$, respectively, which are almost the same. The $\mathrm{R}_{\mathrm{ct}}$ values for the $\mathrm{Fe}_{2} \mathrm{O}_{3} @ \mathrm{CC}$ electrode in $\mathrm{LiNO}_{3}$ and $\mathrm{Ca}\left(\mathrm{NO}_{3}\right)_{2}$ solution are 287.12 and $289.35 \Omega$, respectively. Thereis not strictly parallel to each other in the low-frequencies, indicating similar Warburg impedance. According to the literatures, the $R_{c t}$ value could be usually linked to the diffusive resistance and the distributed resistance of the electrode material, which hints the negligible influences by the nature of electrolyte [25]. Therefore, there is no distinct differences on the EIS between $\mathrm{LiNO}_{3}$ and $\mathrm{Ca}\left(\mathrm{NO}_{3}\right)_{2}$ solution.

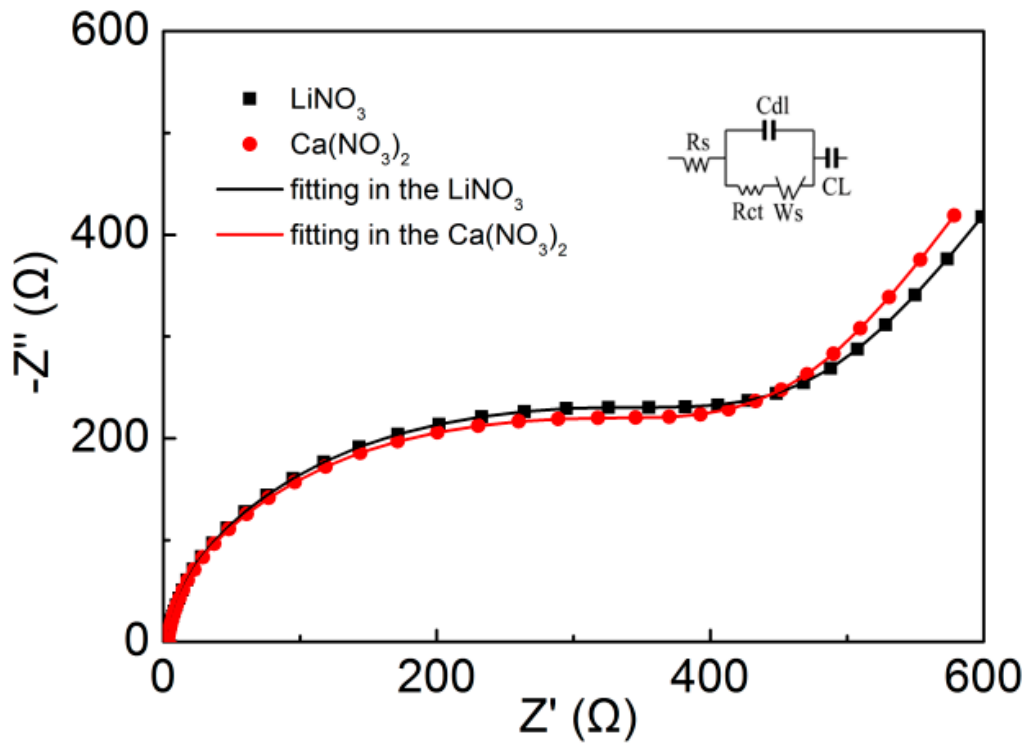

Figure 5. Nyquist plots of the $\mathrm{Fe}_{2} \mathrm{O}_{3} @ \mathrm{CC}$ electrode in aqueous $\mathrm{LiNO}_{3}$ and $\mathrm{Ca}\left(\mathrm{NO}_{3}\right)_{2}$ electrolytes. The circuit for fitting is inserted in the figure.

Lately, Yamada et al. explored a room-temperature hydrate melt of Li salts (LiTFSI + LiBETI) served as aqueous electrolyte, which expanded the stable working voltage window [28]. In this work, $1 \mathrm{M}$ LiTFSI + LiBETI aqueous solution was configured, and used as the electrolyte to investigate the electrochemical performances compared with $1 \mathrm{M} \mathrm{LiNO}_{3}$ aqueous solution. Firstly, Figure 6a depicts $\mathrm{CV}$ curves of the $\mathrm{Fe}_{2} \mathrm{O}_{3} @ \mathrm{CC}$ electrode with different working voltage window in $1 \mathrm{M}$ LiTFSI + 
LiBETI electrolyte. Through expanding the negative voltage from -0.9 to $-1.4 \mathrm{~V}$, we investigate the stable working voltage window of the LiTFSI + LiBETI electrolyte. The CV shape always maintains rectangular-like when expanding the negative voltage from -0.9 to $-1.2 \mathrm{~V}$. With further expanding the negative voltage, the response current increases rapidly, hinting the splitting of water in electrolyte. Thus, the stable working voltage window is -1.2 to $0 \mathrm{~V}$, while it is -0.9 to $0 \mathrm{~V}$ in the above aqueous electrolyte. Then the stability of the $\mathrm{Fe}_{2} \mathrm{O}_{3} @ \mathrm{CC}$ electrode in $1 \mathrm{M}$ LiTFSI + LiBETI is in comparison with that in $1 \mathrm{M} \mathrm{LiNO}_{3}$ solution (Figure $6 \mathrm{~b}$ ). The primary rectangular-like shapes are similar, while a severe polarizationoccurred in $1 \mathrm{M} \mathrm{LiNO}_{3}$ solution due to the easier ions migration than $1 \mathrm{M} \mathrm{LiTFSI}+$ LiBETI with relatively high viscosity. This finding is in accordance with the expanded working voltage window obtained for the room-temperature hydrate melt of Li salts electrolyte.
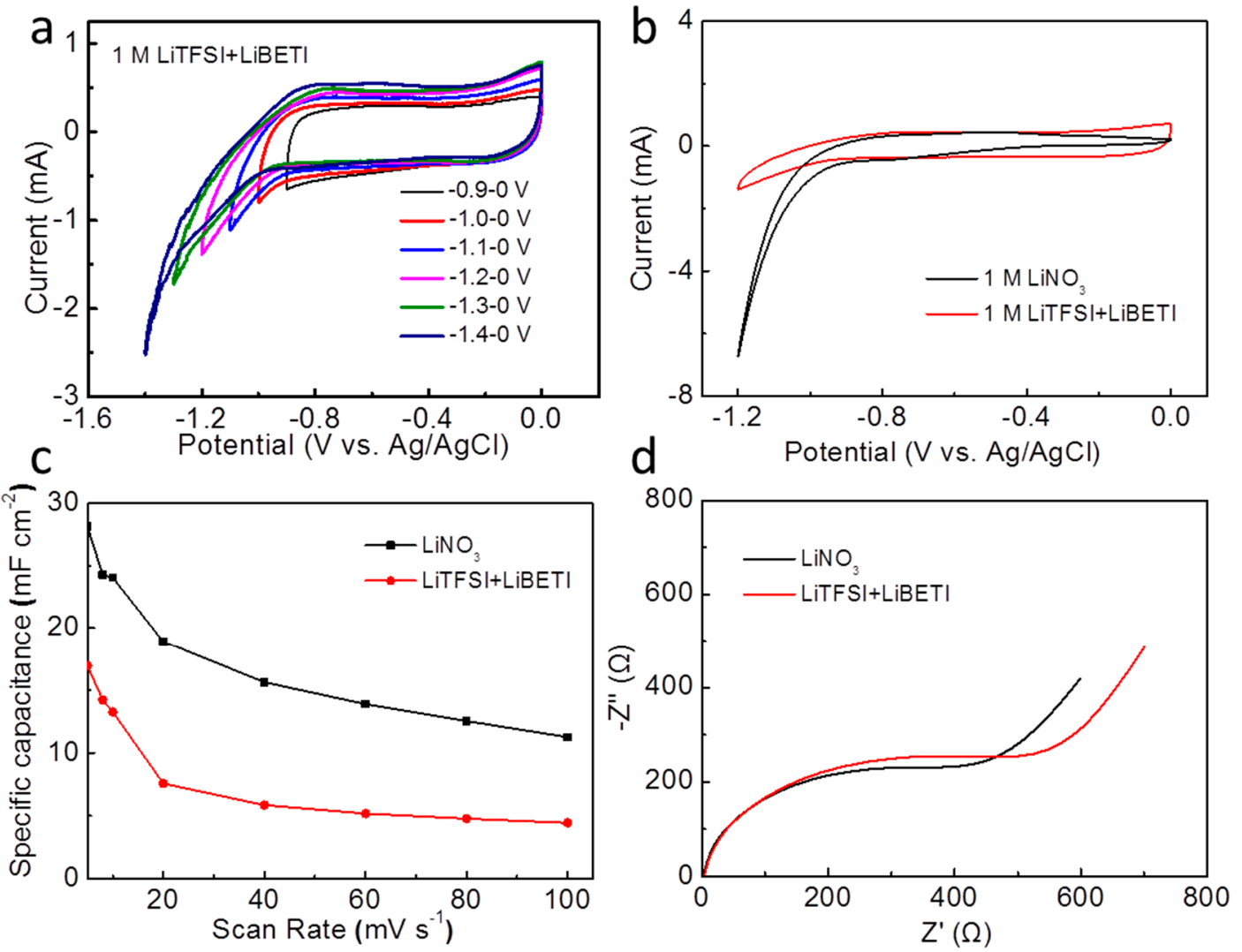

Figure 6. $\mathrm{CV}$ curves of the $\mathrm{Fe}_{2} \mathrm{O}_{3} @ \mathrm{CC}$ electrode: by increasing the negative potential limit from -0.9 to $-1.4 \mathrm{~V}$ in $1 \mathrm{M}$ LiTFSI + LiBETI (a), from -1.2 and $0 \mathrm{~V}$ in $\mathrm{LiNO}_{3}$ and LiTFSI + LiBETI (b), variation of the specific capacitance with the scan rates (c), the Nyquist plots of the $\mathrm{Fe}_{2} \mathrm{O}_{3} @ C C$ electrode in $\mathrm{LiNO}_{3}$ and LiTFSI + LiBETI(d).

The variations of the specific capacitances in these two different electrolytes with the scan rates are exhibited in Figure $6 \mathrm{c}$ to illustrate the electrolytes effects. Not surprisingly, the variation trends of the specific capacitances are similar, and the specific capacitances decrease with increasing the scan rates. Moreover, the specific capacitances in $1 \mathrm{M} \mathrm{LiNO}_{3}$ at all scan rates are higher than that in $1 \mathrm{M}$ LiTFSI + LiBETI, which is due to the lower ionic conductivity, slower ions transportation and diffusion limitation between the electrode and electrolyte. However, the capacitance retention in $1 \mathrm{M} \mathrm{LiTFSI}+$ LiBETI is higher than that in $1 \mathrm{M} \mathrm{LiNO}_{3}$, that is to say, the capacitance attenuation in traditional Li-salt aqueous electrolytes is more significant.

Likewise, the EIS (after fitting) of the $\mathrm{Fe}_{2} \mathrm{O}_{3} @ \mathrm{CC}$ electrode in $1 \mathrm{M}$ LiTFSI + LiBETI electrolyte has been measured to contrast with that in $1 \mathrm{M} \mathrm{LiNO}_{3}$. The whole shapes are similar, which are constituted by a semi-circle and a straight line. By best fitting with the some equivalent circuit in 
Figure 5, the $\mathrm{R}_{\mathrm{S}}$ values for the $\mathrm{Fe}_{2} \mathrm{O}_{3} @ \mathrm{CC}$ electrode in $\mathrm{LiNO}_{3}$ and LiTFSI + LiBETI solution are 2.32 and $3.72 \Omega$, respectively, which are approximatelyequal. The $\mathrm{R}_{\mathrm{ct}}$ values in $\mathrm{LiNO}_{3}$ and LiTFSI $+\mathrm{LiBETI}$ solution are 287.12 and $379.28 \Omega$, respectively. The higher charge transfer resistance may be attributed to the high viscosity and the low ionic conductivity. Thus the straight line in $1 \mathrm{M}$ LiTFSI + LiBETI is more inclined, suggesting larger Warburg impedance. [38] And above all, the EIS plot in 1 M LiTFSI + LiBETI indicates a higher resistance and more difficult ions diffusion than that in $1 \mathrm{M} \mathrm{LiNO}_{3}$.

\section{Conclusions}

In summary, the electrochemical properties of the prepared $\mathrm{Fe}_{2} \mathrm{O}_{3} @ \mathrm{CC}$ electrode have been investigated in various aqueous electrolytes with or without external magnetic field. There is no distinct influence of the larger external magnetic field $(1 \mathrm{~T})$ on the specific capacitance, while the external magnetic field suppresses the water splitting. In addition, the specific capacitances at all scan rates of the $\mathrm{Fe}_{2} \mathrm{O}_{3} @ \mathrm{CC}$ electrode in usual aqueous electrolytes have been virtually unaffected by the chemical valences of the cations. Finally, the $\mathrm{Fe}_{2} \mathrm{O}_{3} @ \mathrm{CC}$ electrode in $1 \mathrm{M}$ LiTFSI + LiBETI electrolyte exhibits a broad working voltage window $(1.2 \mathrm{~V})$, but shows slightly low specific capacitances at all scan rates. This may be due to the high viscosity and low conductivity of the room-temperature molten salts.

Author Contributions: L.G. and Q.D. designed the experiments. L.G. and Z.G. performed the experiments. All authors discussed the results and commented on the manuscript.

Funding: This research was funded by the Program for Innovative Research Team in University of Tianjin (no. TD13-5034), the Plan Program of Tianjin Educational Science and Research (no. 2017KJ087), the National Natural Science Foundation of China (no. 61771340), and Tianjin Natural Science Foundation (17JCQNJC01400).

Acknowledgments: L.G. and Q.D. acknowledge Cuihua An for great helpful discussion.

Conflicts of Interest: The authors declare no competing financial interest.

\section{References}

1. Salanne, M.; Rotenberg, B.; Naoi, K.; Kaneko, K.; Taberna, P.L.; Grey, C.P.; Dunn, B.; Simon, P. Efficient storage mechanisms for building better supercapacitors. Nat. Energy 2016, 1, 16070. [CrossRef]

2. Naoi, K.; Ishimoto, S.; Miyanoto, J.I.; Naoi, W. Second generation 'nanohybrid supercapacitor': Evolution of capacitive energy storage devices. Energy Environ. Sci. 2012, 5, 9363-9373. [CrossRef]

3. EI-Kady, M.; Strong, V.; Dubin, S.; Kaner, R. Laser scribing of high-performance and flexible graphene-based electrochemical capacitors. Science 2012, 335, 1326-1330. [CrossRef] [PubMed]

4. Simon, P.; Gogotsi, Y. Capacitive energy storage in nanostructured carbon-electrolyte systems. Acc. Chem. Res. 2012, 46, 1094-1103. [CrossRef] [PubMed]

5. Lin, T.; Chen, I.; Liu, F.; Yang, C.; Bi, H.; Xu, F.; Huang, F. Nitrogen-doped mesoporous carbon of extraordinary capacitance for electrochemical energy storage. Science 2015, 350, 1508-1513. [CrossRef] [PubMed]

6. Deng, T.; Zhang, W.; Arcelus, O.; Kim, J.; Carrasco, J.; Yoo, S.; Zheng, W.; Wang, J.; Rojo, T. Atomic-level energy storage mechanism of cobalt hydroxide electrode for pseudocapacitors. Nat. Commun. 2017, 8, 15194. [CrossRef] [PubMed]

7. Sheng, T.; Xu, Y.; Jiang, Y.; Huang, L.; Tian, N.; Zhou, Z.; Broadwell, I.; Sun, S. Structure design and performance tuning of nanomaterials for electrochemical energy conversion and storage. Acc. Chem. Res. 2016, 49, 2569-2577. [CrossRef] [PubMed]

8. Sheberla, D.; Bachman, J.; Elias, J.; Sun, C.; Yang, S.; Dinca, M. Conductive MOF electrodes for stable supercapacitors with high areal capacitance. Nat. Mater. 2017, 16, 220-224. [CrossRef] [PubMed]

9. Yang, P.; Ding, Y.; Liu, Z.; Chen, Z.; Li, Y.; Ebrahimi, M.; Mai, W.; Wang, Z. Low-cost high-performance solid-state asymmetric supercapacitors based on $\mathrm{MnO}_{2}$ nanowires and $\mathrm{Fe}_{2} \mathrm{O}_{3}$ nanotubes. Nano Lett. 2014, 14 , 731-736. [CrossRef] [PubMed]

10. Li, Y.L.; Zhu, C.X.; Kan, J.Q. Preparation and characteristics of $\gamma-\mathrm{Fe}_{2} \mathrm{O}_{3} /$ Polyaniline-Curcumin composites. Metals 2015, 5, 2401-2412. [CrossRef] 
11. Liu, L.; Lang, J.; Zhang, P.; Hu, B.; Yan, X. Facile synthesis of $\mathrm{Fe}_{2} \mathrm{O}_{3}$ nano-dots@nitrogen-doped graphene for supercapacitor electrode with ultralong cycle life in $\mathrm{KOH}$ electrolyte. ACS Appl. Mater. Int. 2016, 8, 9335-9344. [CrossRef] [PubMed]

12. Zhang, T.; Wang, H.R.; Zhou, B.; Ji, X.J.; Wang, H.Q.; Du, A. One-dimension diffusion preparation of concentration gradient $\mathrm{Fe}_{2} \mathrm{O}_{3} / \mathrm{SiO}_{2}$ aerogel. Molecules 2018, 23, 1502. [CrossRef] [PubMed]

13. Chaudharl, N.; Chaudharl, S.; Yu, J. Cube-like alpha- $\mathrm{Fe}_{2} \mathrm{O}_{3}$ supported on ordered multimodal porous carbon as high performance electrode material for supercapacitors. ChemSusChem 2014, 7, 3102-3111. [CrossRef] [PubMed]

14. Zhang, Y.G.; Bakenov, Z.; Tan, T.Z.; Huang, J. Synthesis of core-shell carbon encapsulated $\mathrm{Fe}_{2} \mathrm{O}_{3}$ composite through a facile hydrothermal approach and their application as anode materials for sodium-ion batteries. Metals 2018, 8, 461. [CrossRef]

15. Guan, C.; Liu, J.; Wang, Y.; Mao, L.; Fan, Z.; Shen, Z.; Zhang, H.; Wang, J. Iron oxide-decorated carbon for supercapacitor anodes with ultrahigh energy density and outstanding cycling stability. ACS Nano 2015, 9, 5198-5207. [CrossRef] [PubMed]

16. Krysa, J.; Zlamal, M.; Kment, S.; Brunclikova, M.; Hubicka, Z. $\mathrm{TiO}_{2}$ and $\mathrm{Fe}_{2} \mathrm{O}_{3}$ films for photoelectrochemical water splitting. Molecules 2015, 20, 1046-1058. [CrossRef] [PubMed]

17. Liu, Y.; Wang, X.; Qian, G.; Watkins, J. Additive-driven self-assembly of well-ordered mesoporous carbon/Iron oxide nanoparticles composites for supercapacitors. Chem. Mater. 2014, 26, 2128-2137.

18. Lukowskl, M.; Jin, S. Improved synthesis and electrical properties of Si-doped alpha- $\mathrm{Fe}_{2} \mathrm{O}_{3}$ nanowires. J. Phys. Chem. C 2011, 115, 12388-12395. [CrossRef]

19. Li, Y.; Xu, J.; Feng, T.; Yao, Q.; Xie, J.; Xia, H. $\mathrm{Fe}_{2} \mathrm{O}_{3}$ nanoneedles on ultrafine nickel nanotube arrays as efficient anodes for high-performance asymmetric supercapacitors. Adv. Funct. Mater. 2017, 27, 1606728. [CrossRef]

20. Glasscock, J.; Bames, P.; Plumb, I.; Savvides, N. Enhancement of photoelectrochemical hydrogen production from hematite thin films by the introduction of Ti and Si. J. Phys. Chem. C 2007, 111, 16477-16488. [CrossRef]

21. Zhu, J.; Chen, M.; Qu, H.; Luo, Z.; Wu, S.; Colorado, H.; Wei, S.; Guo, Z. Magnetic field induced capacitance enhancement in graphene and magnetic graphene nanocomposites. Energy Environ. Sci. 2013, 6, 194-204. [CrossRef]

22. Zhang, H.X.; Wang, Z.F.; Yang, M.Z.; Deng, Q.B. The effect of an external magnetic field on the dealloying process of the Ni-Al alloy in alkaline solution. Phys. Chem. Chem. Phys. 2017, 19, 18167-18171. [CrossRef] [PubMed]

23. Nayak, P.; Munichandraiah, N. Reversible insertion of a trivalent cation onto $\mathrm{MnO}_{2}$ leading to enhanced capacitance. J. Electrochem. Soc. 2011, 158, A585-A591. [CrossRef]

24. Nayak, P.; Munichandraiah, N. An EQCM investigation of capacitance of $\mathrm{MnO}_{2}$ in electrolytes containing multivalent cations. J. Electroanal. Chem. 2012, 685, 37-40. [CrossRef]

25. Brousse, T.; Toupin, M.; Bélanger, D. A hybrid activated carbon-manganese dioxide capacitor using a mild aqueous electrolyte. J. Electrochem. Soc. 2004, 151, A614-A622. [CrossRef]

26. Long, J.W.; Bélanger, D.; Brousse, T.; Sugimoto, W.; Sassin, M.B.; Crosnier, O. Asymmetric electrochemical capacitors-stretching the limits of aqueous electrolytes. MRS Bull. 2011, 36, 513-522. [CrossRef]

27. Suo, L.; Borodin, O.; Gao, T.; Olguin, M.; Ho, J.; Fan, X.; Luo, C.; Wang, C.; Xu, K. “Water-in-salt" electrolyte enables high-voltage aqueous lithium-ion chemistries. Science 2015, 350, 918. [CrossRef] [PubMed]

28. Yamada, Y.; Usui, K.; Sodeyama, K.; Ko, S.; Tateyama, Y.; Yamada, A. Hydrate-melt electrolytes for high-energy-density aqueous batteries. Nat. Energy 2016, 1, 16129. [CrossRef]

29. Zhao, J.; Li, Y.; Peng, X.; Dong, S.; Ma, J.; Cui, G.; Chen, L. High-voltage Zn/LiMn ${ }_{0.8} \mathrm{Fe}_{0.2} \mathrm{PO}_{4}$ aqueous rechargeable battery by virtue of "water-in-salt" electrolyte. Electrochem. Commun. 2016, 69, 6-10. [CrossRef]

30. Yang, J.; Liu, W.; Niu, H.; Cheng, K.; Ye, K.; Zhu, K.; Wang, G.; Cao, D.; Yan, J. Ultrahigh energy density battery-type asymmetric supercapacitors: NiMoOnanorod-decorated graphene and graphene $/ \mathrm{Fe}_{2} \mathrm{O}_{3}$ quantum dots. Nano Res. 2018, 11, 4744-4758. [CrossRef]

31. Li, T.; Yu, H.; Zhi, L.; Zhang, W.; Dang, L.; Liu, Z.; Lei, Z. Facile electrochemical fabrication of porous $\mathrm{Fe}_{2} \mathrm{O}_{3}$ nanosheets for flexible asymmetric supercapacitors. J. Phys. Chem. C 2017, 121, 18982-18991. [CrossRef]

32. Gao, Y.; Wu, D.; Wang, T.; Jia, D.; Xia, W.; Lv, Y.; Cao, Y.; Tian, Y.; Liu, P. One-step solvothermal synthesis of quasi-hexagonal $\mathrm{Fe}_{2} \mathrm{O}_{3}$ nanoplates/graphene composite as high performance electrode material for supercapacitor. Electrochim. Acta 2016, 191, 275-283. [CrossRef] 
33. Wang, R.; Cai, S.; Yan, Y.; Yourey, W.; Tong, W.; Tang, H. A novel high-performance electrode architecture for supercapacitors: $\mathrm{Fe}_{2} \mathrm{O}_{3}$ nanocube and carbon nanotube functionalized carbon. J. Mater. Chem. A 2017, 5, 22648-22653. [CrossRef]

34. Rani, J.; Thangavel, R.; Oh, S.; Woo, J.; Das, N.; Kim, S.; Lee, Y.; Jiang, J. High volumetric energy density hybrid supercapacitors based on reduced graphene oxide scrolls. ACS Appl. Mater. Int. 2017, 9, 22398-22407. [CrossRef] [PubMed]

35. Nie, G.; Lu, X.; Chi, M.; Zhu, Y.; Yang, Z.; Song, N.; Wang, C. Hierarchical alpha-Fe $\mathrm{O}_{3} @ \mathrm{MnO}_{2}$ core-shell nanotubes as electrode materials for high-performance supercapacitors. Electrochim. Acta 2017, 231, $36-43$. [CrossRef]

36. Raut, S.; Sankapal, B. Comparative studies on MWCNTs, $\mathrm{Fe}_{2} \mathrm{O}_{3}$ and $\mathrm{Fe}_{2} \mathrm{O}_{3} / \mathrm{MWCNTs}$ thin film towards supercapacitor application. New J. Chem. 2016, 40, 2619-2627. [CrossRef]

37. Mosqueda, H.; Crosnier, O.; Athouël, L.; Dandeville, Y.; Scudeller, Y.; Guilemet, P.; Schleich, D.; Brousse, T. Electrolytes for hybrid carbon- $\mathrm{MnO}_{2}$ electrochemical capacitors. Electrochim. Acta 2010, 25, 7479-7483. [CrossRef]

38. Gambou-Bosca, A.; Belanger, D. Electrochemical characterization of $\mathrm{MnO}_{2}$-based composite in the presence of salt-in-water and water-in-salt electrolytes as electrode for chemical capacitors. J. Power Sources 2016, 326, 595-603. [CrossRef]

(C) 2018 by the authors. Licensee MDPI, Basel, Switzerland. This article is an open access article distributed under the terms and conditions of the Creative Commons Attribution (CC BY) license (http:/ / creativecommons.org/licenses/by/4.0/). 